\title{
Analysis of submerged implant towards mastication load using 3D finite element method (FEM)
}

\author{
Widya Hafsyah Sumarlina Ritonga*, Janti Rusjanti**, Nunung Rusminah**, Aldilla \\ Miranda**, Tatacipta Dirgantara*** \\ *Bandung Special Dental Hospital Ministry of Health Republic of Indonesia \\ **Department of Periodontics Faculty of Dentistry Universitas Padjadjaran Indonesia \\ ***Department of Light Aeromechanical Structure Faculty of Mechanical and Aerospace Engineering \\ Institut Teknologi Bandung Indonesia
}

\begin{abstract}
Introduction: The surgical procedure of dental implant comprising one stage surgery for the nonsubmerged implant design and two stages for submerged. Submerged design is frequently used in Faculty of Dentistry Padjadjaran University as it is safer in achieving osseointegration. This study has been carried out to evaluate resistant capacity of an implant component design submerged against failure based on location and the value of internal stress during the application of mastication force using the 3D Finite Element Method (FEM). Methods: The present study used a CBCT radiograph of the mandibular patient and Micro CT Scan of one submerged implant. Radiograph image was then converted into a digital model of 3D computerized finite element, subsequently inputted the material properties and boundary condition with $87 \mathrm{~N}$ occlusion load applied and about $29 \mathrm{~N}$ for the shear force. Results: The maximum stress was found located at the contact area between the implant and alveolar crest with stress value registered up to $193.31 \mathrm{MPa}$ located within an implant body where is understandable that this value is far below allowable strength of titanium alloy of $860 \mathrm{MPa}$. Conclusion: The location of the maximum stress was located on the contact area between the implant-abutment and alveolar crest. This implant design is acceptable and no failure observed under mastication load.
\end{abstract}

Keywords: Stress value, submerged implant, mastication load, 3D finite element method

\section{INTRODUCTION}

The replacement of the missing tooth with root form implant become one of the most significant improvements in restorative dentistry history. Implant performance and durability are dependently determined by the osseointegration process, which was introduced in 1952 by Branemark saying that the dental implant that was united with the bone (osteointegration) has a high success rate to restore the masticatory and aesthetics function of toothless patients. ${ }^{1-5}$

Surgical technique of dental implants can be done through one stage surgical procedure (non-submerged) or two stages (submerged). For the submerged implant placement, healing of soft tissue around the implant take place at the same time with osseointegration. The threaded implant portion is inserted as deep as the top of the bone so that the mucoperiosteal flap can be closed over 
the buried implant. The second stage was carried out the placement of healing abutment through opening the mucosal tissue. ${ }^{6-8}$ This implant type is commonly used in Faculty of Dentistry Padjadjaran University up today.

Implant and abutment was basically two components that is mix up by a screw, this interface has a gap of about 10 microns, and therefore the failure of the implant therapy frequently occur at the connection between the abutment and the implant due to broken or looseness of the screw. Such failures occur due to an increase of unpredictable loading on the implant, abutment and screw. ${ }^{9-11}$ Stress transfer mechanism and the failure of the osseointegration is influenced by the micro gap control, implant geometry, the surgical process of the implant placement, and the presence of excess load (overloading) on the bone. It is difficult to evaluate clinically, so that needed another methods that can analyze the mechanism of stress transfer and failure of implant components. ${ }^{12.13}$

Finite Element Methods (FEM) have been widely used to predict the distribution and value of stress in the implant region, investigating the influence of implant design, the magnitude and direction of the load, as well as the mechanical properties of bone. This numerical technique is also being used in analyzing the effectiveness and reliability of implants, implant failure, and implant-bone structure mechanical interaction. ${ }^{9}$ Through biomechanical approach, researchers wanted to analyze the to failure (fracture) of submerged implant design based on the location and value of the stress due to mastication loading using 3D FEM.

\section{METHODS}

Type of this research is an observational descriptive research using 3D FEM. The materials used include: $C B C T$ image of mandible patient that containing embedded osseointegrated implant and the Micro CT scan image of the Osstem ${ }^{\circledR}$ TSIII implant submerged design.

The procedure of this method is described below, as follow: First stage, the preparation of the CBCT photo implant patients and CT scan of the lower jaw of the patient was taken after a CT Scan osseointegrated and body micro implant and abutment of the Osstem ${ }^{\circledR}$ implant submerged design TSIII type. Second stage was geometry modeling of three dimensional, the aim of this stage is to construct images of three-

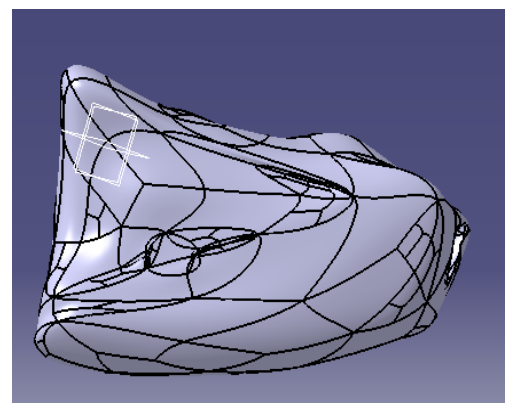

A

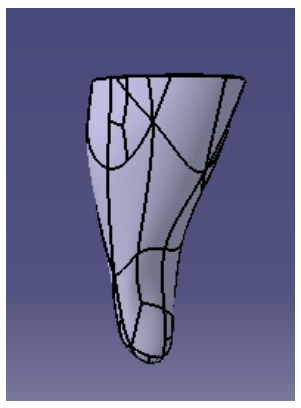

D

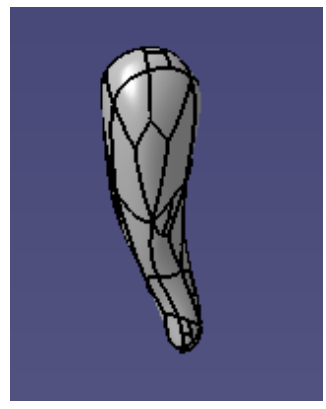

B

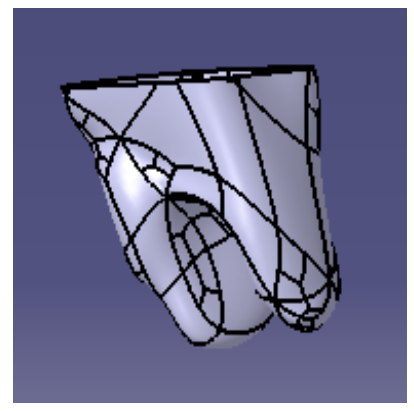

E

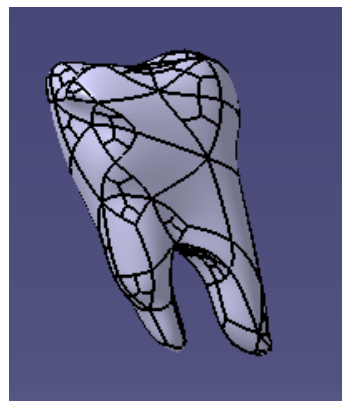

C

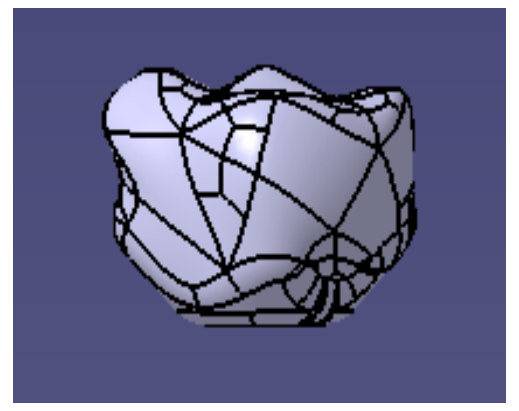

$\mathrm{F}$

Figure 1. Model 3D geometry dental components: lower molar alveolar bone; (b) second premolar teeth; (c) second molar teeth; (d) periodontal dental ligament p2; (e) second molar periodontal ligament; (f) first molar dental prosthesis. 


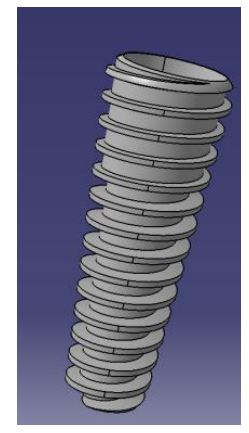

A

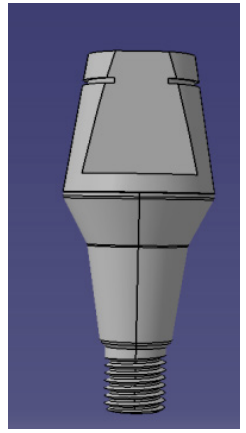

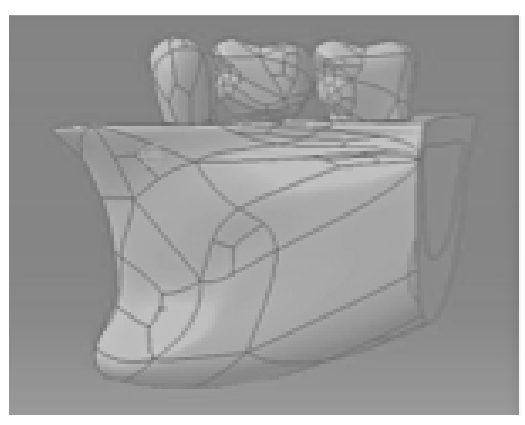

C

Figure 2. Model 3D Geometry Submerged Implant Components: A. Implant Body; B. Abutment; C. Model Results The whole Assembly Components.

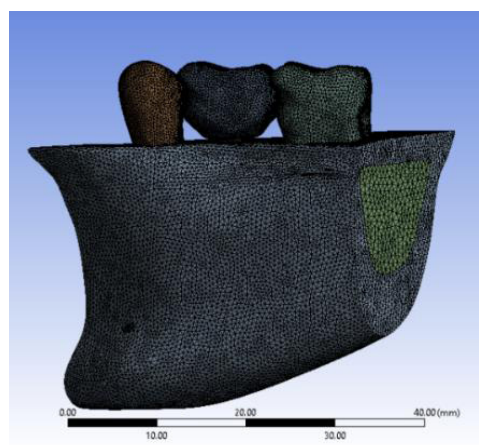

A

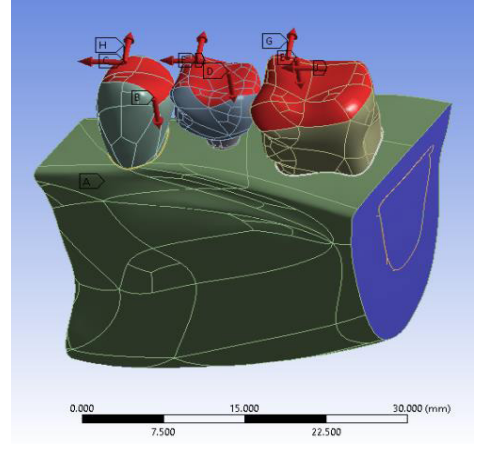

B

Figure 3. Model of finite element: A. Meshing results; B. Simulation Imposition on occlusal surface.

dimensional geometry of the lower jaw bone (cortical and trabecular bone), second premolars and second molars, periodontal ligament, body implants, abutments and prostheses. Meanwhile, the modeling of dental components, implant components, and prostheses is done separately.

Third stage: modeling component dental and protesa. This stage is to make an images of three-dimensional geometry of the lower jaw bones (bone cortical and trabecular), dental second premolar and second molar, periodontal ligament, and the prosthesis which is done by transforming the picture image of $\mathrm{CBCT}$ mandible patient to three-dimensional digital model by using finite element software-DOCTOR ${ }^{\circledR}$ and CATIA V5R19 ${ }^{\circledR}$ (Fig. 1). The Implant Component used in this study was TSIII Osstem type (TS3S4011S) brand implants with $11.5 \mathrm{~mm}$ height, $4.0 \mathrm{~mm}$ platform diameter and $2.8 \mathrm{~mm}$ body diameter. Type abutment used is GSRA5620 with outer diameter $4.8 \mathrm{~mm}$, gingival height $2 \mathrm{~mm}$ and 5.5 $\mathrm{mm}$ head height. Abutment threaded part has an internal thread size, the diameter of the pitch
$1.74 \mathrm{~mm}, 0.4 \mathrm{~mm}$ pitch distance and angle screw $60^{\circ}$. Modeling of the implants body and abutments are using CATIA V5R19 software ${ }^{\circledR}$ (Fig. 2).

Apart from above, Merging Solid Model (Model Assembly) components of teeth, dentures, and implant components into a complete three-dimensional geometry model of the jaw submerged implants implanted patients are using CATIA V5R19 software ${ }^{\circledR}$ (Fig. 3). Ultimately, the whole Finite Element Modeling, carried out using ANSYS 17.1 software ${ }^{\circledR}$. The procedure begins by converting the three-dimensional geometry model that has been done using software CATIA assembly V5R19 ${ }^{\circledR}$ software into the ANSYS ${ }^{\circledR} 17.1$ and then do the meshing (the division of the model into small elements) (Fig. 4).

Fourth stage: Afterward, all material properties for the static analysis of each component (Table 1) as well as determine the boundary conditions (environment) can be done in the form of pedestal types and styles of working. The type of pedestal used is a fixed pedestal which is located on both ends of the lower jaw surface. 
Table 1. Data material properties

\begin{tabular}{|c|c|c|c|c|}
\hline Name & Material & Modulus of elasticity (MPa) & Poisson's ratio & Slide modulus (MPa) \\
\hline Prothesis & Feldsphatic Porcelain & 61200 & 0.19 & \\
\hline Implant body and Abutment & Ti-6Al-4V & 110,000 & 0.32 & \\
\hline Alveolar bone & Cortical & $\begin{array}{l}E_{x} 12,600 \\
E_{y} 12,600 \\
E_{z} 19,400\end{array}$ & $\begin{array}{l}V_{x y} 0.300 \\
V_{y z} 0.253 \\
V_{x z} 0.253\end{array}$ & $\begin{array}{l}G_{x y} 4,850 \\
G_{y z} 5,700 \\
G_{x z} 5,700\end{array}$ \\
\hline Alveolar bone & Trabecular & $\begin{array}{l}E_{x} 1,148 \\
E_{y} 210 \\
E_{z} 1,148\end{array}$ & $\begin{array}{l}V_{x y} 0.055 \\
V_{y z} 0.010 \\
V_{x z} 0.322\end{array}$ & $\begin{array}{l}G_{x y} 68 \\
G_{y z} 68 \\
G_{x z} 434\end{array}$ \\
\hline Molar & Dentin & 18,600 & 0.35 & \\
\hline Periodontal ligament & Periodontal ligament & 50 & 0.49 & \\
\hline
\end{tabular}

Table 2. Data number of elements of convergence test results

\begin{tabular}{lc}
\hline \multicolumn{1}{c}{ Component } & Number of elements \\
\hline Prothesa & 108459 \\
Abutment & 67794 \\
Implant Agency & 34239 \\
Second Premolar & 104235 \\
Second Molar & 128994 \\
Second Premolar Periodontal Ligament & 61480 \\
Second Molar periodontal ligament & 207106 \\
Cortical Bone & 294155 \\
Trabecular Bones & 100192 \\
\hline
\end{tabular}
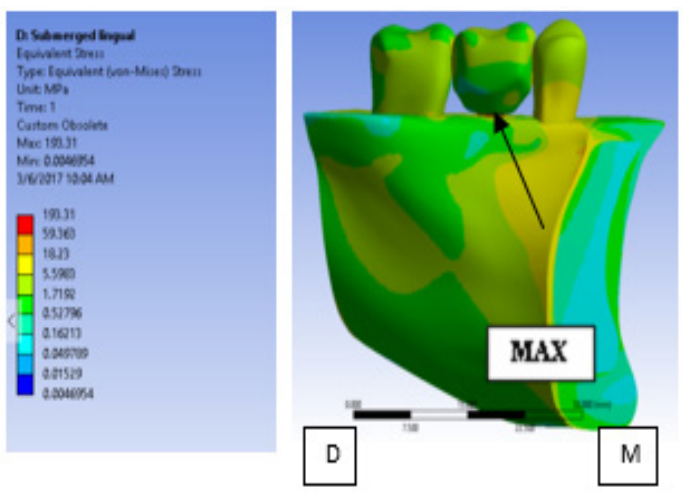

A
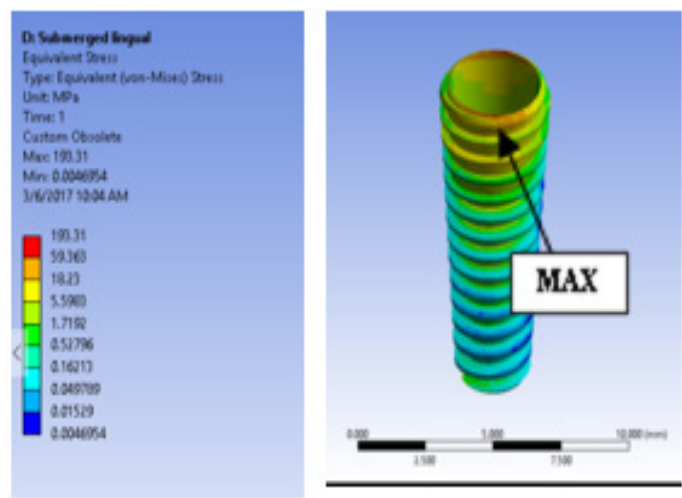

B

Figure 4. Maximum tension location on: A. Model component; B. Body implants

The load simulation applied to the model is a load simulation that is similar to the process of mastication where the load applied to the model consists of an occlusion load and a shear load with $3: 1$ ratio, which are $87 \mathrm{~N}$ and $29 \mathrm{~N}$ respectively (Fig. 5).

Fifth stage: The next stage is a convergence test to obtain the number of elements in which a component has a test result leading to a certain value with the smallest error with a $99 \%$ confidence level (Table 2).
Sixth stage: Running/solving, this stage is made to exhibit the desired output analysis include: location of maximum stress with color code that is distributed to each component of the model as well as obtaining a maximum stress value that occurs in the component models. From this stage, the researcher are able to interpret and analyze the location as well as the stress values to evaluate the robustness of submerged design implant component toward it failure (fracture) mode due to mastication loading. 


\section{RESULTS}

This study was carried out to enable further understanding of location and maximum stress value that could possibly occurs in the implant submerged components and periodontal tissue. The results are presented both using qualitative and quantitative analysis. Qualitative analysis has been done by looking at the color pattern where the red color indicates the location of the maximum von-Mises stress that occurs. The location of maximum stress was found located at implant body more particularly at the joining area between implant body and abutment (crest module) with alveolar bone crest (Fig. 6 and 7).

Other than that, the quantitative analysis has been done by evaluating the maximum stress value within the area of implant component. That value is then compared against the strength of the materials to evaluate performance and resistant capacity of an implant component design submerged against failure due to mastication force, exactly at the implant body and abutment. The maximum von-Mises stress of submerged design was found at the implant body with registered stress up to $193.31 \mathrm{MPa}$, meanwhile in abutment are goes up to $134.62 \mathrm{MPa}$. Its fully understandable that this maximum value of vonMises stress in the implant components are far below the yield strength value of titanium alloy (860 MPa).

\section{DISCUSSION}

This study has been carried out using 3D FEM, to evaluate resistant capacity of an implant component design submerged against failure due to mastication force by analyzing the value and location of the maximum stress. The location of maximum stress was located in implant body more particularly at the joining area between implant body and abutment joint (crest module) with alveolar bone crest.

The design of the implant components itself will affect location and the value of maximum stress where for the submerged implant design there is no part of implant body that is protruding from alveolar bone crest. Other than that, position of implant neck toward alveolar bone crest was also one of main governing factor that control the stress distribution pattern. Referring to study made by Huang's ${ }^{15}$ related to stress distribution at 20 type of implant which has different in the mounting position toward alveolar bone crest, the result of the study clearly shows that the stress value for the implant with the implant's neck above alveolar bone crest has always higher stress compare to one sitting on top of alveolar bone crest. ${ }^{15}$ Ormianer ${ }^{16}$ and Zamani ${ }^{17}$ in their research about stress and strain distribution pattern for implant system 1-piece (non-submerged) and 2-piece (submerged) resulting obtain similar stress concentration distribution for both that is at the area of alveolar bone crest. The reason to that might be due to critical joint between two different component that has different physical properties between bone material and titanium alloy, other than that is because of significant gap between prosthesis crest to the abutment and implant body joint in the submerge design ${ }^{3}$

Stress concentrations that were located at contact area between crest bone and implant body-abutment joint are due to sudden geometrical changes at the area within crest module and alveolar crest bone. According to Hermann ${ }^{18}$, these changes were influenced by the microgap between alveolar bones with the implant component.

The internal stress value is also determined by the modulus of young (stiffness) of the material. The dental implant was made from the titanium alloy with modulus of young five to six times larger than the cortical bone. The principle technique called composite beam states that when two materials with different elastic modulus are placed together and then one of the materials is stressed, the material with stiffer member will attract more stress, which could lead to the increasing stress at that particular location. This principle is in accordance with the phenomenon that occurs in the interface area between the bone-implant and alveolar bone crest. This phenomenon can be observed through photoelasticity and FEM analysis. ${ }^{19}$

\section{CONCLUSION}

The location of the maximum stress was located on the contact area between the implantabutment and alveolar crest. This implant design 
is acceptable and no failure observed under mastication load.

\section{REFERENCES}

1. Newman MG, Takei HH, Klokkevold PR, Carranza FA. Clinical periodontology. $10^{\text {th }}$ ed. St. Louis: Elsevier; 2006.

2. Lindhe J, Karring T, Lang NP. Clinical periodontology and implant dentistry. $5^{\text {th }}$ ed. Oxford: Blackwell Munksgaard; 2008.

3. Misch KE. Contemporary implant dentistry. St. Louis Missouri: Mosby Elsevier; 2008.

4. Al-Sabbagh M. Implants in esthetic zone. Dent Clin N Am 2006Jul:50(3):391-407.

5. Zhang G, Yuan H. Chen X, Wang W, Chen J, Liang $J$, et al. A Three-dimensional finite element study on the biomechanical simulation of various structured dental implants and their surrounding bone tissues. Int J Dent; 2016.

6. Baggi L, Cappelloni I, Di Girolamo M, Maceri F, Vairo G. The influence of implant diameter and length on tension distribution of osseointegrated implant related to crestal bone geometry: A three-dimensional finite element analysis. J Prosthet Dent; 2008Dec:100(6):422-31.

7. Buser D, Bernard JP. Implant in the load carrying part of the dentition, In: Lee $D$. Research on the clinical result of Koreas Avana implant. J Korean Dent Ass 2000;38(6):460-70.

8. Drago C. Implant restorations: A step-by-step guide. $2^{\text {nd }}$ ed. Blackwell Munksgaard; 2007.

9. Yeshwante B, Patil S, Baig N, Gaikwad S, Swami A, Doiphode M. Dental implant-clasification, success and failure-an overview. IOSR J Dent Med Sci 2015 May:14(5):1-8. Available from: http: //www.iosrjournals.org.

10. Segundo RMH, Oshima HMS, Silva INL, Junior LHB, Mota EG, Coelho LFB. Stress distribution on external hexagon implant system using $3 D$ finite element analysis. Acta Odontol Latinoam 2007:20(2):79-81.

11. Taylor TD, Agar JA, Vogiatzi T. Implant prosthodontics: current perspective and future directions. Int J Oral Maxillofac Implant 2000:15(1):66-75.

12. Seth S, Kalra P. Effect of dental implant parameters on tension distribution at boneimplant interface. Int J Sci Res 2013:2(6):12-4.
13. Abrahams JJ, Hayt MW, Rock R. Sinus lift procedure of the maxilla in patient with inadequate bone for dental implants. Am J Roentgenol 2000:174:1289-92.

14. Kayabasi O, Yuzbasioglu E, Erzincanli F. Static, dynamic and fatique behaviors of dental implants using finite element method. Adv Eng Softw. 2006;37(10):649-58.

15. Huang HL, Chang CH, Hsu JT, Fallgatter AM, Ko CC. Comparison of implants body designs and threaded designs of dental implants: a 3-dimensional finite element analysis. Int $\mathrm{J}$ Oral Maxillofac Implants 2011;22(4):551-62.

16. Ormianer Z, Amar Z, Duda AB, Marku-Cohen $M$, Lewinstein SI. Stress and strain patterns of 1-piece and 2-piece implant systems in bone: a 3-dimensional finite element analysis. Implant Dent 2012;21:(1):1-7.

17. Zamani S. One piece and two piece implant demonstrate comparable tension levels in bone: preliminary results of an FEA study. Calsbad, CA: Zimmer Dental Inc.; 2008. p. 1-2.

18. Hermann JS, Buser D, Schenk RK, Cochran DL. Crestal bone changes around titanium implant. A histometric evaluation of unloaded nonsubmerged and submerged implants in the canine mandible. J Periodontol 2000; 71(9):1412-24.

19. Perrella M, Franciosa P, Gerbino S. FEM and BEM tension analysis of mandibular bone surrounding a dental implant. Open Mechan Eng J 2015;9:282-92.

20. Ishigaki S, Nakano T, Yamada S, Takashima F. Biomechanical tension in bone surrounding an implant under simulated mastication. Clin Oral Implant Res; 2003Feb;14(1):97-102.

21. Eskitascioglu G, Usumez A, Sevimay M, Soykan $E$, Unsal $E$. The influence of occlusal loading location on tensiones transfered to implantsupported prostheses and supporting bone: A three dimentional finite element study. J Prosthet Dent 2004 Feb;91(2):144-50.

22. Kitamura E, Stegariou R, Namura S, Miyakawa $O$. Influence of marginal bone resorption on tension around an implant-a three dimentional finite element anaysis. J Oral maxillofac Implants 2003;18:447-52.

23. Akca C, Cehreli MK. Biomechanical consequences of progressive marginal bone loss around oral implants: a finite elements 
tension analysis. Med Biol Eng Comput 2006; 44:527-35.

24. Adell R, Lekholm U, Gröndahl K, Brånemark $\mathrm{PI}$, Lindström J, Jacobsson M. Reconstruction of severely resorbed edentulous maxillae using osseointegrated fixtures in immediate autogeneous bone grafts. Int J Oral Maxillofac Implant 1990;5(3):233-46. 